\title{
The influence of muscle-tendon forces on $A C L$ loading during jump landing: a systematic review
}

\author{
Katja Oberhofer ${ }^{1}$ \\ S. H. Hosseini Nasab ${ }^{1}$ \\ Pascal Schütz ${ }^{1}$ \\ Barbara Postolka ${ }^{1}$ \\ Jess G. Snedeker ${ }^{1,2}$ \\ William R. Taylor ${ }^{1}$ \\ Renate List ${ }^{1}$ \\ 1 Institute for Biomechanics, ETH Zürich, Switzerland \\ 2 University Hospital Balgrist, Zürich, Switzerland
}

Corresponding author:

Katja Oberhofer

Institute for Biomechanics

Leopold-Ruzicka-Weg 4, HCP H 21.2 ETH

8093 Zürich, Switzerland

E-mail: katja.oberhofer@hest.ethz.ch

\section{Summary}

Background: The goal of this review is to summarise and discuss the reported influence of muscle-tendon forces on anterior cruciate ligament (ACL) loading during the jump-landing task by means of biomechanical analyses of the healthy knee.

Methods: A systematic review of the literature was conducted using different combinations of the terms "knee”, “ligament”, “load”, “tension ", "length", “strain", "elongation" and "lengthening", 26 original articles $(n=16$ in vitro studies; $n=10$ in situ studies) were identified which complied with all inclusion/exclusion criteria.

Results: No apparent trend was found between $A C L$ loading and the ratio between hamstrings and quadriceps muscle-tendon forces prior to or during landing. Four in vitro studies reported reduced peak ACL strain if the quadriceps force was increased; while one in vitro study and one in situ study reported reduced ACL loading if the hamstrings force was increased. A meta-analysis of the reported results was not possible because of the heterogeneity of the confounding factors.

Conclusion: The reported results suggest that increased hip flexion during landing may help in reducing $A C L$ strain by lengthening the hamstrings, and thus increasing its passive resistance to stretch. Furthermore, it appears that increased tensile stiffness of the quadriceps may help in stabilising the knee joint during landing, and thus protecting the passive soft-tissue structures from overloading.

Level of evidence: Ib.

KEY WORDS: anterior cruciate ligament, high-impact activities, knee, loading patterns, musculoskeletal control.

\section{Introduction}

Rupture of the anterior cruciate ligament $(A C L)$ is a common sports injury, and is especially associated with jump-landing tasks and side-step cutting activities such as basketball, soccer or tennis ${ }^{1-3}$. Despite the successes of $A C L$ reconstruction surgery, up to $90 \%$ of patients continue to develop early osteoarthritis within 20-years post-surgery ${ }^{4}$. This is an alarmingly high number given that patients with $A C L$ injuries are often young athletes or adults who are fit and healthy. Interestingly, a high percentage of ACL ruptures occurs in non-contact situations, indicating that ACL injuries are likely influenced by poor neuromuscular control and improper movement execution rather than an external impact force delivered directly to the knee joint ${ }^{1-3}$. In general, female athletes seem to exhibit a greater incidence of non-contact ACL injury compared to male counterparts, which has been associated with the females' reduced capability to stabilise the joint during high-impact movements ${ }^{5}$. From a biomechanical perspective, the strains and loading in the ACL during dynamic movement are predominantly governed by the forces and moments that are applied to the knee joint, the instantaneous position and orientation of the lower limbs, as well as the non-linear material properties of the bone and soft tissue. An important aspect to consider is that slight changes of kinematic or kinetic parameters at the ankle or the hip joint can play a critical role on the loading of the knee joint, and thus on ACL strains and forces. This is especially important for the jump-landing task (also referred to as jump landing in the literature), which is characterised by a large vertical ground reaction force that mainly induces an ankle dorsiflexion moment, a knee flexion moment, and a hip flexion moment, whereby the triceps surae, the quadriceps and the hamstrings are the key muscletendon groups to counteract the externally induced flexion moments ${ }^{4}$. 
Several major reviews have been published to summarise recent advances and insights into ACL loading from biomechanical analyses (including computational modelling, cadaveric testing, robotic simulations and in vivo measurements). In particular, Kazemi et al. ${ }^{6}$ provided a general review of computational models to analyse the mechanical function of the knee joint during different loading conditions; Pappas et al. ${ }^{7}$ summarised available techniques to measure ligament strain and forces in vivo with an emphasis on their advantages, limitations, and clinical relevance; and Bates et al. ${ }^{4}$ provided a summary of the literature on the biomechanical evidence regarding ACL loading during physiological or clinical tasks from in vitro cadaveric simulations. The latter group further conducted a meta-analysis of the reported ACL forces during passive knee flexion, in which a strong correlation was found between anterior-tibial translation and ACL ligament forces during passive knee flexion ${ }^{4}$. It was further confirmed that combined joint movements with coupled knee flexion, abduction and internal tibial rotation generally had a greater impact on ACL loading than isolated conditions alone, which is in line with the findings from epidemiological studies in female athletes that report higher knee valgus, hip internal rotation, and hip adduction during landing compared to male counterparts 8,9 .

To date most studies and reviews have focused on the relationship between joint kinematics and $A C L$ loading, i.e. how differences in joint position and orientation affect ACL strain and forces. However, the relationship between joint kinetics (including muscletendon forces and moments) and ACL loading is less well known, probably due to the challenges in measuring these dynamic parameters in vivo. As noted in a recent review, limitations remain in accurately replicating the dynamic muscle-tendon forces and moments that act on the knee joint during high-impact movements, which may have led to physiologically inaccurate conclusions in the past ${ }^{4}$. ACL injuries commonly occur during high-impact sporting activities that are associated with significantly different muscle activation patterns compared to passive knee motion or low-impact movements such as squatting or gait. Here, muscle-tendon forces are thought to play a key role in stabilising the knee joint ${ }^{10}$, and thus impacting on ACL loading through dynamic force coupling. Thereby, the ratio between the hamstrings and the quadriceps muscle-tendon force $(\mathrm{H}: \mathrm{Q}$ ratio) may be related to the magnitude of $A C L$ loading during landing. In particular, it has been previously proposed that lower $\mathrm{H}: \mathrm{Q}$ ratios may lead to reduced knee stability that is associated with higher ACL strains ${ }^{11}$. However, such hypotheses are largely based on results from epidemiological or modelling studies; and speculation remains as to how the complex interactions of lower limb motion, muscle-tendon forces and moments influence ACL loading during high-impact dynamic situations in vivo.

In recent years, efforts have been directed towards improving cadaveric measurement and computational modelling techniques to accurately replicate muscletendon and joint dynamics when analysing ACL strain during high-impact sporting activities. In particular, improvements in cadaveric testing apparatus, as well as advancements in multi-body computational simulations of the musculoskeletal system, have provided novel approaches for analysing the influence of muscle-tendon forces and moments on ACL loading during jump landing. However, no consensus has been reached as to the relationship between muscle-tendon forces, joint kinematics, kinetics and ACL loading during dynamic movement in vivo. Here, clear insights would be crucial to confirm previously posed hypotheses on muscle activity from epidemiological studies, improve the general understanding of noncontact ACL rupture, and eventually advance effective injury prevention and/or treatment. The goal of this systematic review is therefore to summarise, compare and evaluate the findings from these novel experimental and computational techniques and gather biomechanically-based evidence on the influence of muscle-tendon forces on ACL loading during highimpact movements such as landing from a vertical jump. Results on ACL strain and forces during jump landing from cadaveric and computational studies were compiled from the literature with a special focus on the associated muscle-tendon forces that were applied at the knee joint during in vitro or in situ dynamic simulation.

\section{Material and methods}

\section{Literature search}

This research was ethically conducted according to international standards and as described in ${ }^{12}$. PubMed, Embase, and Cochrane databases were searched from their inception to November 2014 to identify studies that reported on ACL loading during jump landing. Different combinations of the terms "knee", "ligament", "load", "tension ", "length", "strain", "elongation" and "lengthening" were used. To facilitate the conduct of the systematic review and the identification of duplicate reports, all search results were imported into Eppireviewer (version 4) ${ }^{13}$. The titles and abstracts of all identified citations were screened and the full texts of all potentially eligible studies were retrieved. The initial search was not restricted to the ACL but included all knee joint ligaments to avoid missing articles which included load data on the ACL in the full text without reporting it in the title or the abstract. Studies were included in the full text review if they satisfied all inclusion/exclusion criteria as outlined below. The reference lists of all retrieved studies were further screened for additional relevant articles.

\section{Inclusion/exclusion criteria}

To be included in this review, studies had to present original data of either ACL strain or ACL forces during jump landing. In order to focus this review on the re- 
lationship between ACL loading and acting muscletendon forces, studies were only included if they additionally presented the magnitude of at least one muscle-tendon force prior to or during landing. Inclusion of studies was limited to analyses of healthy knees with intact ligaments. Data collected in the pathological knee or after clinical intervention (including but not limited to tibial osteotomy, posterior cruciate ligament resection, or meniscus resection) were excluded. Non-original research, reports on the work of others, non-English articles and abstracts were also excluded.

\section{Extraction of data}

Numerical data were extracted from those studies that reported on most of the following parameters in addition to ligament strain or forces: peak vertical impact force (VIF), knee flexion angle, hip flexion angle, anterior tibial translation (ATT), $\mathrm{H}: \mathrm{Q}$ ratio before landing, and peak $H: Q$ ratio during landing. Here, the choice of parameters reflects the focus of this review on the key biomechanical parameters associated with jump landing. The retrieved data included numerical values that were specifically given in the literature, as well as approximated values that could be derived from the presented graphs and given data. Subject number, average age and weight were also retrieved from the literature if possible. A meta-analysis of the reported findings was not performed due to the heterogeneity of the confounding factors, in particular large inter-study differences in the magnitudes of the peak VIF and the lower limb position at initial contact across the literature.

\section{Results}

The initial literature search yielded a total of 2371 articles to be considered for the review (Fig. 1). A total of 2155 studies was excluded after initial screening. The full texts of the remaining 216 studies were retrieved for further evaluation. Screening of the fulltext articles revealed that only 68 articles contained load data on the ACL. After carefully reading the full text articles, a total of 24 studies was identified that complied with all inclusion/exclusion criteria. 44 of the 68 studies were excluded because they reported on ACL loading during gait $(n=14)$, other low-impact loading $(n=21)$, side-step cutting $(n=2)$, or isolated un-physiological force application $(n=3)$. Four studies were further excluded because they did not specifically report on the magnitudes of the applied muscle forces during jump landing ${ }^{14-17}$. After screening of the reference lists, a further two papers were identified that complied with all inclusion/exclusion criteria. This yielded a total of 26 papers that were included in this re-

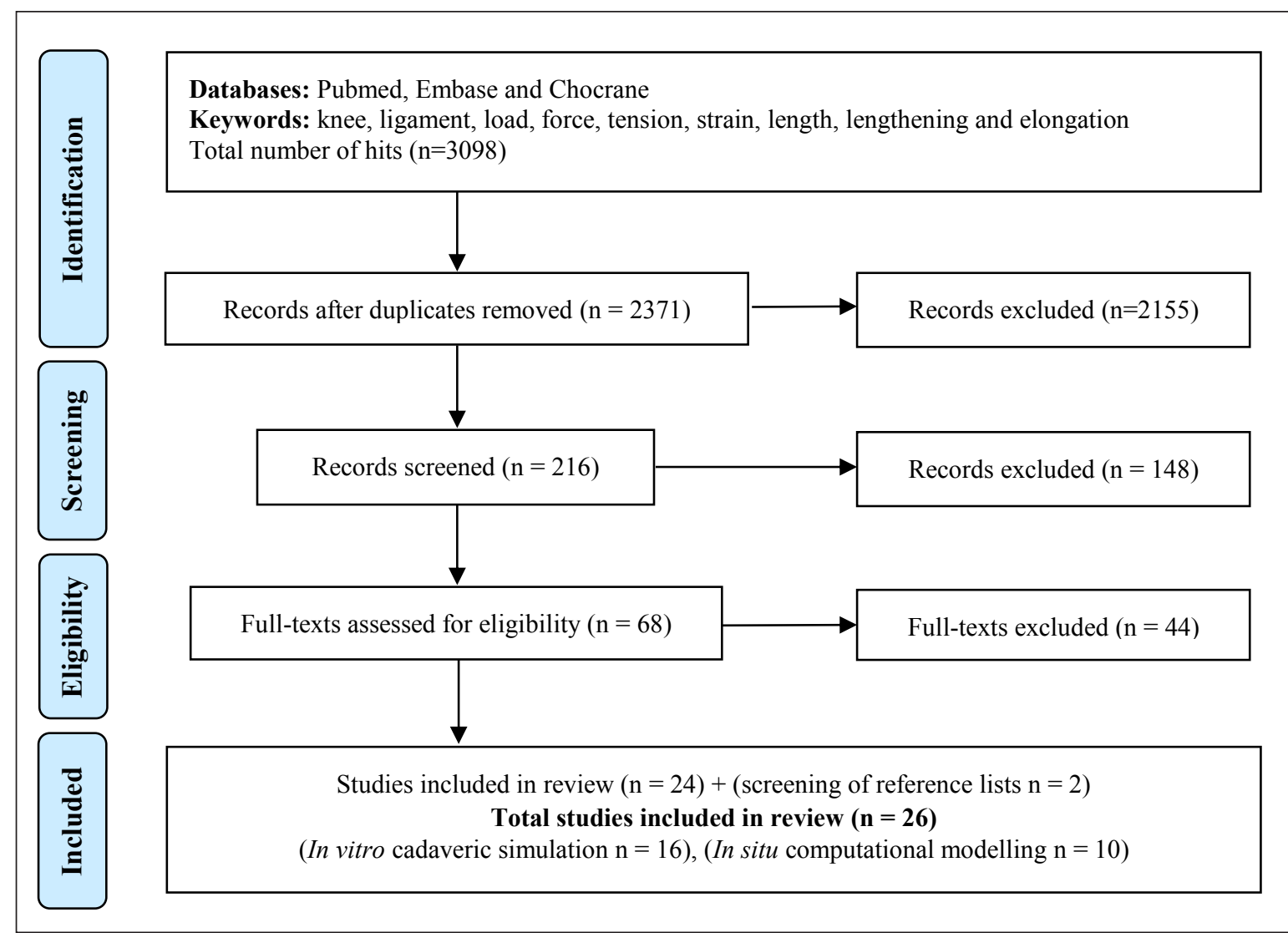

Figure 1. PRISMA flowchart of the systematic review ${ }^{45}$. 
view, whereby 16 studies reported on results from in vitro cadaveric testing and 10 studies from in situ computational modelling. Two studies were found that analysed in vivo ACL strain by either combining markerbased motion analysis with MRI-based computational modelling and fluoroscopic imaging ${ }^{16}$, or direct measurements based on an implanted DVRT device ${ }^{14}$. Unfortunately, both in vivo studies were limited to kinematic data without reporting on muscle-tendon forces, and were thus excluded from the review.

\section{Relationship between muscle-tendon forces and in vitro $A C L$ strain during jump landing}

A total of 16 full-text articles reported on ACL strain in the anterio-medial bundle (AM-ACL strain), as well as presented the force magnitudes of at least one muscle-tendon structure, during single- and/or doublelegged drop landing using cadaveric simulators and measurements from differential variable reluctance transducers (DVRT) placed in the anterio-medial bundle of the ACL (Tab. I). The most commonly applied cadaveric simulator was introduced by Withrow et al. ${ }^{18}$, and used to analyse AM-ACL strain during jump landing in approximately 90 cadaveric specimens ${ }^{18-}$ 26 . To replicate the passive muscle forces during jump landing, the quadriceps, hamstrings and gastrocnemius tendons were attached in series to aircraft cables with a known stiffness and pretension ${ }^{18}$. Here, the $30-80 \mathrm{~ms}$ time of single-leg landing was considered too short for any muscle reflex or substantial volitional changes in muscle activation to occur. Thus, the representation of the muscle stretch response to loading using nonlinear passive springs was considered valid. Later modifications to the initial design of the Withrow testing apparatus included the replacement of the aircraft cables with nonlinear springs to account for the muscle's bilinear elastic and viscous resistance to rapid stretch during dynamic movement ${ }^{21,24}$, as well as the consideration of the external hip rotator muscles, in addition to the quadriceps, hamstrings and gastrocnemius ${ }^{19}$.

The reported results on peak relative strain and strain rate in the AM-ACL during jump landing using the cadaveric testing simulator by Withrow et al. ${ }^{18}$ are provided in Table II. Here, 'relative strain' was defined as the change in DVRT length from the initial length in the pre-impact static posture, divided by the initial length. Thereby, the ACL was always preloaded in the initial configuration and the unloaded zero strain state was unknown ${ }^{18}$. The $\mathrm{H}: \mathrm{Q}$ ratio prior to landing was set at 0.39 for all simulations, with the knee positioned at either $15^{\circ}$ or $25^{\circ}$ flexion angle pre-impact. The peak VIF that was applied to simulate jump landing ranged from $622 \mathrm{~N}^{21}$ to $2093 \mathrm{~N}^{26}$. It is important to note, that the foot was not included in the Withrow testing apparatus with the VIF applied directly to the tibia of the cadaveric leg. The resulting peak relative AM-ACL strain spanned a wide range that could not be explained by differences in the applied VIF, e.g. $0.8 \%$ peak relative $\mathrm{AM}-\mathrm{ACL}$ strain at a peak VIF of $2093 N^{26}$ versus $8.69 \%$ peak relative AM-ACL strain at a peak VIF of $1196 \mathrm{~N}^{19}$. Contradictory results were also reported between the $H: Q$ ratio during landing and the peak relative AM-ACL strain, with two studies reporting a positive correlation 20,21 and one study reporting a negative correlation ${ }^{26}$. It appears that an increase in the forces of the hamstrings or the quadriceps muscle-tendon unit during jump landing may cause a decrease in the resulting peak relative AMACL strain. In particular, Withrow et al. ${ }^{26}$ reported a decrease in the peak relative AM-ACL strain of $>70 \%$ in ten cadaveric knees if the peak hamstring forces during landing were increased by $100 \%$; while Lipps et al. ${ }^{21}$ showed that an increase in the tensile stiffness of the quadriceps muscle-tendon unit by $33 \%$ led to a decrease in the peak relative AM-ACL strain of $16 \%$ in 12 female cadaveric knees despite an ATT increase. Lipps et al. ${ }^{20}$ further reported an increase in the peak relative AM-ACL strain of $95 \%$ in ten female cadaveric specimens compared to ten male cadaveric specimens, with the muscle-tendon tensile stiffness of the quadriceps for the sample of female specimens being reduced by $20 \%$ to reflect in vivo data on gender differences in muscle properties attributable to smaller muscle mass in the female.

Another in vitro cadaveric testing apparatus to simulate jump landing was introduced by Levine et al. ${ }^{27}$ and used in the same or a subset of eight male and eight female cadaveric specimens to analyse the relationship between AM-ACL strain and multi-planar knee kinematics 28,29 as well as loading conditions and injury patterns at point of ligament failure ${ }^{27,29}$. It should be noted that the exact number of specimens is difficult to extract from the literature because subject-specific characteristics are not always fully detailed, and thus, several studies may have used the same specimens. Muscle-tendon structures in the Levine testing apparatus were replicated using cablepulley systems that allowed static force application along the lines-of-action of the quadriceps and hamstring muscle groups ${ }^{27}$. Here, muscle-tendon forces were mainly applied to stabilize the knee joint prior to the simulation of landing, without reporting or analysing their influence on ACL loading during simulation. The $H: Q$ ratio to stabilise the knee prior to landing was set at 0.66 for all simulations, with the knee positioned at $25^{\circ}$ flexion angle at touch down ${ }^{27}$ 30. The foot of the cadaveric leg in the Levine testing apparatus was included to accurately capture the load transfer at the ankle joint with the VIF ranging from $3775 \mathrm{~N}$ to $4875 \mathrm{~N}^{27-30}$, which is substantially higher than the VIF applied to the tibia in the cadaveric simulator by Withrow et al. ${ }^{18}$ (Tab. II). The resulting peak relative $\mathrm{AM}-\mathrm{ACL}$ strain ranged from 9.4 to $27 \%$, which is also substantially higher compared to the results reported in ${ }^{19,21-26}$. It is likely that the larger strain magnitudes are due to the larger VIF magnitudes as well as differences in simulating the contribution of muscle-tendon forces prior to and during landing. Yet, an analytical comparison was not possible due to large inter-study differences in experimental set-up. Further in vitro cadaveric simulators were developed by Weinhold et al. ${ }^{31}$ and Hashemi et al. ${ }^{5}$, with the latter also being used in a study by Cassidy et al. ${ }^{32}$ us- 
Table I. In vitro studies using cadaveric simulators to analyse ACL strain during jump landing. Ham: hamstrings; Quad: quadriceps; Gastro: gastrocnemius; F: female; M: male; y: years; CSA: cross-sectional area.

\begin{tabular}{|c|c|c|c|c|}
\hline Ref & Activity & Muscles & Subjects & Focus/independent variable \\
\hline [19] & $\begin{array}{l}\text { Single-legged } \\
\text { landing }\end{array}$ & $\begin{array}{l}\text { Ham, quad, hip } \\
\text { rotators }\end{array}$ & $\begin{array}{l}10 \mathrm{~F}, 55.2 \mathrm{y}, 10 \mathrm{M} \\
59.9 \mathrm{y}\end{array}$ & $\begin{array}{l}\text { Limited internal femoral } \\
\text { rotation }\end{array}$ \\
\hline [32] & $\begin{array}{l}\text { Double- } \\
\text { legged } \\
\text { landing }\end{array}$ & $\begin{array}{l}\text { Ham, quad, } \\
\text { gastro }\end{array}$ & $1 F, 20 y / 1 M, 43 y$ & Dynamic in vivo loading \\
\hline [5] & $\begin{array}{l}\text { Double- } \\
\text { legged } \\
\text { landing }\end{array}$ & Quad & $4 \mathrm{~F}, 5 \mathrm{M}, 55.1 \mathrm{y}$ & Quadriceps pre-activation \\
\hline [28] & $\begin{array}{l}\text { Double- } \\
\text { legged } \\
\text { landing }\end{array}$ & Ham, quad & $8 \mathrm{~F}, 8 \mathrm{M}, 45 \mathrm{y}^{\star}$ & $\begin{array}{l}\text { Time-sequence of knee } \\
\text { kinematics }\end{array}$ \\
\hline [29] & $\begin{array}{l}\text { Double- } \\
\text { legged } \\
\text { landing }\end{array}$ & Ham, quad & $6 \mathrm{~F}, 8 \mathrm{M}, 45 \mathrm{y}^{*}$ & $\begin{array}{l}\text { Passive anterior knee joint } \\
\text { laxity }\end{array}$ \\
\hline [27] & $\begin{array}{l}\text { Single- and } \\
\text { double-legged } \\
\text { landing }\end{array}$ & Ham, quad & $9 \mathrm{~F}, 8 \mathrm{M}, 45 \mathrm{y}^{*}$ & $\begin{array}{l}\text { Injury mechanisms (multi- } \\
\text { planar kinematics) }\end{array}$ \\
\hline [21] & $\begin{array}{l}\text { Single-legged } \\
\text { landing }\end{array}$ & Ham, quad & $12 \mathrm{~F}, 58 \mathrm{y}, 70.2 \mathrm{~kg}$ & Quadriceps stiffness \\
\hline [20] & $\begin{array}{l}\text { Single-legged } \\
\text { landing }\end{array}$ & Ham, quad & $\begin{array}{l}10 \mathrm{~F}, 65.7 \mathrm{y}, 10 \mathrm{M} \\
60.8 \mathrm{y}\end{array}$ & $\begin{array}{l}\text { Gender-specific muscle } \\
\text { stiffness, ACL CSA \& lateral } \\
\text { tibial slope }\end{array}$ \\
\hline [22] & $\begin{array}{l}\text { Single-legged } \\
\text { landing }\end{array}$ & $\begin{array}{l}\text { Ham, quad, } \\
\text { gastro }\end{array}$ & $11 \mathrm{~F}, 65 \mathrm{y}$ & $\begin{array}{l}\text { Anterior tibial acceleration \& } \\
\text { posterior tibial slope }\end{array}$ \\
\hline [23] & $\begin{array}{l}\text { Single-legged } \\
\text { landing }\end{array}$ & $\begin{array}{l}\text { Ham, quad, } \\
\text { gastro }\end{array}$ & $8 \mathrm{~F}, 4 \mathrm{M}, 65 \mathrm{y}$ & Axial tibial torque \\
\hline [24] & $\begin{array}{l}\text { Single-legged } \\
\text { landing }\end{array}$ & $\begin{array}{l}\text { Ham, quad, } \\
\text { gastro }\end{array}$ & $6 \mathrm{~F}, 9 \mathrm{M}, 70.4 \mathrm{y}$ & $\begin{array}{l}\text { Axial tibial torque \& frontal } \\
\text { plane moment }\end{array}$ \\
\hline [30] & $\begin{array}{l}\text { Single- and } \\
\text { double-legged } \\
\text { landing }\end{array}$ & Ham, quad & $9 \mathrm{~F}, 8 \mathrm{M}, 45 \mathrm{y}^{*}$ & $\begin{array}{l}\text { Injury mechanisms (multi- } \\
\text { planar kinematics) }\end{array}$ \\
\hline [31] & $\begin{array}{l}\text { Double- } \\
\text { legged } \\
\text { landing }\end{array}$ & Ham, quad & $\begin{array}{l}7 \text { age/gender } \\
\text { unknown }\end{array}$ & Gender-specific loading \\
\hline [26] & $\begin{array}{l}\text { Single-legged } \\
\text { landing }\end{array}$ & $\begin{array}{l}\text { Ham, quad, } \\
\text { gastro }\end{array}$ & $6 \mathrm{~F}, 4 \mathrm{M}, 60.3 \mathrm{y}$ & Hamstring tension \\
\hline [18] & $\begin{array}{l}\text { Single-legged } \\
\text { landing }\end{array}$ & $\begin{array}{l}\text { Ham, quad, } \\
\text { gastro }\end{array}$ & $5 \mathrm{~F}, 5 \mathrm{M}, 67.9 \mathrm{y}$ & Valgus moment \\
\hline [25] & $\begin{array}{l}\text { Single-legged } \\
\text { landing }\end{array}$ & $\begin{array}{l}\text { Ham, quad, } \\
\text { gastro }\end{array}$ & $6 \mathrm{~F}, 5 \mathrm{M}, 70.8 \mathrm{y}$ & $\begin{array}{l}\text { Quadriceps force, impact } \\
\text { force, knee flexion }\end{array}$ \\
\hline
\end{tabular}

${ }^{*}$ Possibly same or subgroup of same cadaveric specimens

ing physiologically-based muscle force profiles from in vivo inverse dynamics analysis. Here, the muscletendon forces of the hamstrings and quadriceps determined in an amateur female athlete were trans- ferred to a cadaveric knee joint to measure AM-ACL strain magnitudes during jump landing, with a reported peak relative $\mathrm{AM}-\mathrm{ACL}$ strain of $4.3 \%$ during landing. Comparing the muscle force trajectories with the 
Table II. In vitro results from cadaveric experiments (cadaveric simulator based $\mathrm{n}^{18}$ ) on peak relative AM-ACL strain [\%] and strain rate [\%/s] of the ACL during jump landing with corresponding loading conditions. Values in grey are approximated from the available, published data or graphs. IC: initial contact; VIF: vertical impact force; ATT: anterior tibial translation; $\mathrm{H}: \mathrm{Q}$ : hamstrings to quadriceps force ratio; $\mathrm{F}$ : female; $\mathrm{M}$ : male; y: years.

\begin{tabular}{|c|c|c|c|c|c|c|c|c|c|c|}
\hline Ref & Subjects & $\begin{array}{c}\text { Peak } \\
\text { relative } \\
\text { strain [\%] }\end{array}$ & $\begin{array}{c}\text { Strain } \\
\text { rate } \\
{[\% / s]}\end{array}$ & $\begin{array}{l}\text { Time } \\
\text { after } \\
\text { IC }\end{array}$ & $\begin{array}{c}\text { Peak } \\
\text { VIF [N] }\end{array}$ & $\begin{array}{c}\text { H:Q } \\
\text { before } \\
\text { IC }\end{array}$ & $\begin{array}{c}\text { Peak } \\
H: Q\end{array}$ & $\begin{array}{c}\text { Knee } \\
\text { flexion } \\
\text { at IC }\end{array}$ & $\begin{array}{c}\text { Knee } \\
\text { flexion } \\
\text { at } \\
\text { peak } \\
\text { ACL }\end{array}$ & $\begin{array}{c}\text { Peak } \\
\text { ATT } \\
{[\mathrm{mm}]}\end{array}$ \\
\hline \multirow[t]{2}{*}{ [19] } & $10 F, 55.2 y$ & 8.7 & $\mathrm{n} / \mathrm{a}$ & $\begin{array}{l}0.005- \\
0.01\end{array}$ & 1196 & 0.39 & $n / a$ & 15 & 21.9 & $4.1-7.6$ \\
\hline & $10 \mathrm{M}, 59.9 \mathrm{y}$ & 6.0 & $\mathrm{n} / \mathrm{a}$ & $\begin{array}{l}0.005- \\
0.02\end{array}$ & 1416 & & $\mathrm{n} / \mathrm{a}$ & & 22.4 & $0.5-7$ \\
\hline \multirow[t]{2}{*}{ [21] } & $\begin{array}{l}12 \mathrm{~F}, 58 \mathrm{y} \\
70.2 \mathrm{~kg}\end{array}$ & 6.0 & 232.4 & 0.01 & 622 & 0.39 & $x$ & 15 & 25.1 & 4.9 \\
\hline & & 5.0 & 156.2 & 0.01 & 652 & & $0.90 \mathrm{X}$ & & 23 & 5.4 \\
\hline \multirow[t]{2}{*}{ [20] } & $\begin{array}{l}10 \mathrm{~F}, 65.7 \mathrm{y} \\
68.8 \mathrm{~kg}\end{array}$ & 6.4 & 232.4 & 0.027 & 688 & 0.39 & $Y$ & 15 & 23.9 & 4.0 \\
\hline & $\begin{array}{l}10 \mathrm{M}, 60.8 \mathrm{y} \\
71.8 \mathrm{~kg}\end{array}$ & 3.3 & 156.2 & 0.021 & 814 & & $0.84 Y$ & & 21.5 & 3.4 \\
\hline [22] & $11 F, 65 y$ & 3.4 & $\mathrm{n} / \mathrm{a}$ & 0.066 & 1298 & 0.39 & $\mathrm{n} / \mathrm{a}$ & $\mathrm{n} / \mathrm{a}$ & $\mathrm{n} / \mathrm{a}$ & $\mathrm{n} / \mathrm{a}$ \\
\hline [23] & $8 \mathrm{~F}, 4 \mathrm{M}, 65 \mathrm{y}$ & 3.0 & 184.2 & 0.075 & 1287 & 0.39 & $\mathrm{n} / \mathrm{a}$ & 15 & 29.6 & 1.3 \\
\hline [24] & $\begin{array}{l}6 \mathrm{~F}, 9 \mathrm{M}, 70.4 \mathrm{y} \\
85.6 \mathrm{~kg}\end{array}$ & 3.8 & $\mathrm{n} / \mathrm{a}$ & 0.071 & 1457 & 0.39 & $\mathrm{n} / \mathrm{a}$ & 15 & 29.4 & 1.6 \\
\hline \multirow[t]{4}{*}{ [26] } & $6 \mathrm{~F}, 4 \mathrm{M}, 60.3 \mathrm{~kg}$ & 3.0 & $\mathrm{n} / \mathrm{a}$ & $\begin{array}{l}0.03- \\
0.06\end{array}$ & 1755 & 0.39 & 0.11 & 25 & 30.9 & 4.3 \\
\hline & & 0.8 & $\mathrm{n} / \mathrm{a}$ & & 2093 & & 0.31 & & 30.5 & 3.1 \\
\hline & & 3.6 & $\mathrm{n} / \mathrm{a}$ & & 1777 & & 0.06 & & 31 & 4.2 \\
\hline & & 2.9 & $\mathrm{n} / \mathrm{a}$ & & 1702 & & 0 & & 31.1 & 4.8 \\
\hline [18] & $5 F, 5 M, 67.9 y$ & 3.5 & $\mathrm{n} / \mathrm{a}$ & $\begin{array}{l}0.02- \\
0.05\end{array}$ & 1610 & 0.39 & $\mathrm{n} / \mathrm{a}$ & 25 & 29.7 & 1.9 \\
\hline [25] & $6 \mathrm{~F}, 5 \mathrm{M}, 70.8 \mathrm{y}$ & 2.9 & $\mathrm{n} / \mathrm{a}$ & $\begin{array}{l}0.02- \\
0.05\end{array}$ & 1400 & 0.39 & $\mathrm{n} / \mathrm{a}$ & 25 & 30.9 & $\mathrm{n} / \mathrm{a}$ \\
\hline
\end{tabular}

AM-ACL strain trajectories during landing, it was found that the AM-ACL strain was low at peak quadriceps force during landing ${ }^{32}$. In different work, Hashe$\mathrm{mi}$ et al. ${ }^{5}$ reported a decrease in AM-ACL strain from 4.5 to $2.8 \%$ with an increase in quadriceps muscle force from $25 \mathrm{~N}$ to $700 \mathrm{~N}$ during landing in nine cadaveric knees ( 5 males, 4 females, average age 55.1 years), even though AM-ACL strain was increased prior to landing in the presence of higher quadriceps forces. These results are in line with the results by Lipps et al. 20,21 suggesting that the quadriceps muscle-tendon unit acts as joint stabiliser during landing, and thus assists in reducing ligament loading. Yet, an analytical analysis of the reported relationship between quadriceps forces and AM-ACL strain was again difficult due to large inter-study differences in the confounding factors, i.e. magnitudes of the VIF.

Relationship between muscle-tendon forces and in situ ACL forces during jump landing

A total of 10 studies reported on ACL loading, including applied muscle force magnitudes, during singlelegged $(n=5)$ or double-legged $(n=5)$ jump landing based on musculoskeletal, computational modelling of the knee joint or the lower limbs (Tab. III). Thereby, computational models with different degrees of com- 
Table III. In silico computational modelling studies that analysed ACL loading during jump landing. Ham: hamstrings; Quad: quadriceps; Gastro: gastrocnemius; ID: inverse dynamics; FD: forward dynamics; CMC: computed muscle control; F: female; M: male; y: years.

\begin{tabular}{|c|c|c|c|c|c|}
\hline Ref & Activity & Muscles & Method & Subjects & $\begin{array}{l}\text { Focus/independent } \\
\text { variable }\end{array}$ \\
\hline [11] & $\begin{array}{l}\text { Double-legged } \\
\text { landing }\end{array}$ & $\begin{array}{l}\text { Rectus fem, biceps } \\
\text { fem }\end{array}$ & $\begin{array}{l}\text { In vivo, ID/FD, } \\
\text { CMC }\end{array}$ & $\begin{array}{l}11 \mathrm{~F}, 20 \mathrm{y} \\
59.7 \mathrm{~kg}\end{array}$ & Increased drop height \\
\hline [37] & $\begin{array}{l}\text { Double-legged } \\
\text { landing }\end{array}$ & $\begin{array}{l}\text { Ham, gastro, patellar } \\
\text { tendon }\end{array}$ & $\begin{array}{l}\text { In vivo, ID, EMG- } \\
\text { driven }\end{array}$ & $\begin{array}{l}16 \mathrm{~F}, 22 \mathrm{y} \\
62.2 \mathrm{~kg}\end{array}$ & Muscle \& joint forces \\
\hline [33] & $\begin{array}{l}\text { Double-legged } \\
\text { landing }\end{array}$ & Ham, quad & $\begin{array}{l}\text { 3D FEM } \\
\text { cadaveric } \\
\text { experiments }\end{array}$ & $8 \mathrm{~F}, 8 \mathrm{M}, 45 \mathrm{y}$ & $\begin{array}{l}\text { Validation of cadaveric } \\
\text { experiments }\end{array}$ \\
\hline [38] & $\begin{array}{l}\text { Single-legged } \\
\text { landing }\end{array}$ & Ham, patellar tendon & $\begin{array}{l}\text { In vivo, ID/FD, } \\
\mathrm{CMC}\end{array}$ & $\begin{array}{l}15 \mathrm{~F}, 20.9 \mathrm{y} \\
63.2 \mathrm{~kg}^{*}\end{array}$ & Stiff versus soft landing \\
\hline [39] & $\begin{array}{l}\text { Single-legged } \\
\text { landing }\end{array}$ & $\begin{array}{l}\text { Ham, quad, gastro, } \\
\text { soleus }\end{array}$ & $\begin{array}{l}\text { In vivo, ID, static } \\
\text { optimisation }\end{array}$ & $\begin{array}{l}8 \mathrm{M}, 22.9 \mathrm{y} \\
67.2 \mathrm{~kg}\end{array}$ & Gastrocnemius \& soleus \\
\hline [40] & $\begin{array}{l}\text { Double-legged } \\
\text { landing }\end{array}$ & $\begin{array}{l}\text { Gastro, tibialis, } \\
\text { vastus, rectus fem, } \\
\text { ham, biceps fem }\end{array}$ & $\begin{array}{l}\text { In vivo, ID, EMG- } \\
\text { driven }\end{array}$ & $1 \mathrm{M}, 28 \mathrm{y}, 82 \mathrm{~kg}$ & $\begin{array}{l}\text { Lower limb force } \\
\text { transmission }\end{array}$ \\
\hline [36] & $\begin{array}{l}\text { Single-legged } \\
\text { landing }\end{array}$ & Ham, quad, gastro & $\begin{array}{l}\text { Force-driven } \\
\text { model }\end{array}$ & $\mathrm{n} / \mathrm{a}$ & $\begin{array}{l}\text { Valgus \& internal rotation } \\
\text { moments }\end{array}$ \\
\hline [34] & $\begin{array}{l}\text { Single-legged } \\
\text { landing }\end{array}$ & Ham, quad, gastro & $\begin{array}{l}\text { Force-driven } \\
\text { model }\end{array}$ & $\mathrm{n} / \mathrm{a}$ & $\begin{array}{l}\text { Posterior deceleration } \\
\text { force }\end{array}$ \\
\hline [35] & $\begin{array}{l}\text { Single-legged } \\
\text { landing }\end{array}$ & Ham, quad, gastro & $\begin{array}{l}\text { Force-driven } \\
\text { model }\end{array}$ & $\mathrm{n} / \mathrm{a}$ & Valgus moment \\
\hline [41] & $\begin{array}{l}\text { Double-legged } \\
\text { landing }\end{array}$ & $\begin{array}{l}\text { Ham, gastro, patellar } \\
\text { tendon }\end{array}$ & $\begin{array}{l}\text { In vivo, ID, EMG- } \\
\text { driven }\end{array}$ & $\begin{array}{l}23 \mathrm{~F}, 20.9 \mathrm{y} \\
63.1 \mathrm{~kg}^{*}\end{array}$ & $\begin{array}{l}\text { Knee \& hip flexion during } \\
\text { landing }\end{array}$ \\
\hline
\end{tabular}

* possible same or subgroup of same subjects

plexities have been developed, either alongside cadaveric testing to extend the experimental results ${ }^{23,33-}$ ${ }^{36}$, or in combination with in vivo measurements of joint kinematics, external ground reaction forces and muscle-tendon forces to investigate the factors contributing to ACL loading during jump landing 11,37-41. Here, the open-source musculoskeletal modelling software OpenSim ${ }^{42}$ was used in three studies to derive the muscle-tendon forces during landing based on in vivo kinematic, kinetic and EMG data, whereby one study adopted an algorithm based on static optimisation ${ }^{39}$ while two studies deployed an advanced algorithm called computed muscle control ${ }^{11,38}$. In comparison to the standardised position of the knee joint and constant pre-tension of muscles $(\mathrm{H}: \mathrm{Q}$ ratio) for in vitro studies, the reported muscle-tendon forces and knee joint kinematics from in situ computational modelling varied significantly between studies (Tab. IV), with the $H: Q$ ratio prior to impact ranging from 0.33 to 1.33 , the initial knee flexion angle from $9^{\circ}$ to $34^{\circ}$ and the peak VIF from 1.8 to 4.1 times Body Weight (BW). Furthermore, computational simulations were often driven by in vivo data from optical motion capture, ground reaction force measurements and

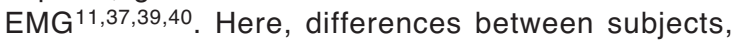

testing procedures and data processing likely contributed to the larger range of input parameters compared to cadaveric testing.

The results from in situ computational modelling suggest that there is no apparent trend between the resulting peak $A C L$ force and the peak VIF or the $\mathrm{H}: \mathrm{Q}$ ratio prior to or during the landing phase (Tab. IV). Note, data was only extracted from those studies that reported on most of the following parameters in addition to ligament forces: VIF, knee flexion angle, hip flexion angle, ATT, $H: Q$ ratio before landing and peak $H: Q$ ratio during landing. The reported peak $A C L$ force ranged from $0.15 B W$ with $1.8 B W$ of peak VIF and $0.19 \mathrm{H}: \mathrm{Q}$ peak ratio during landing ${ }^{37}$ to $0.8 \mathrm{BW}$ with $3.3 \mathrm{BW}$ of peak VIF and $0.76 \mathrm{H}: \mathrm{Q}$ peak ratio during landing ${ }^{38}$. Interestingly, the results by Southard et al. ${ }^{41}$ suggest that increased tension in the hamstrings due to greater hip flexion angles are likely to contribute to a reduction in ACL loading. This finding is in line with the in vitro results by Withrow et al. ${ }^{26}$, who reported reduced peak AM-ACL strain with increased passive stiffness of the hamstrings, suggesting that greater hip flexion during landing may help to increase the muscles' force generating capacity to reduce anterior shear forces, and thus contribute to reduced ACL loading. 
Table IV. Results from in silico computational modelling on peak ACL force during jump landing with corresponding loading conditions. Values in grey are approximated from the available, published data or graphs. IC: initial contact; BW: body weight; VIF: vertical impact force; ATT: anterior tibial translation; H:Q: hamstrings to quadriceps force ratio; F: female; M: male; y: years.

\begin{tabular}{|c|c|c|c|c|c|c|c|c|c|c|c|}
\hline Ref & Subjects & $\begin{array}{c}\text { Peak } \\
\text { ACL } \\
\text { force } \\
\text { [BW] }\end{array}$ & $\begin{array}{c}\text { Time } \\
\text { after } \\
\text { IC }\end{array}$ & $\begin{array}{c}\text { Peak } \\
\text { VIF } \\
{[B W]}\end{array}$ & $\begin{array}{c}\text { H:Q } \\
\text { before } \\
\text { IC }\end{array}$ & $\begin{array}{l}\mathrm{H}: \mathrm{Q} \\
\text { peak }\end{array}$ & $\begin{array}{c}\text { Knee } \\
\text { flexion } \\
\text { at IC }\end{array}$ & $\begin{array}{c}\text { Knee } \\
\text { flexion } \\
\text { at } \\
\text { peak } \\
\text { ACL }\end{array}$ & $\begin{array}{c}\text { Hip } \\
\text { flexion } \\
\text { at IC }\end{array}$ & $\begin{array}{c}\text { Hip } \\
\text { flexion } \\
\text { at } \\
\text { peak } \\
\text { ACL }\end{array}$ & $\begin{array}{c}\text { ATT } \\
\text { increase }\end{array}$ \\
\hline [37] & $\begin{array}{l}16 \mathrm{~F}, 22 \mathrm{y} \\
62.6 \mathrm{~kg}\end{array}$ & 0.2 & 0.07 & 1.8 & 0.56 & 0.19 & 18 & $30-50$ & $n / a$ & $\mathrm{n} / \mathrm{a}$ & $\mathrm{n} / \mathrm{a}$ \\
\hline \multirow[t]{2}{*}{ [38] } & $\begin{array}{l}15 \mathrm{~F}, \\
20.9 \mathrm{y}, \\
63.2 \mathrm{~kg}\end{array}$ & 0.8 & 0.01 & 3.3 & 1.33 & 0.76 & 11 & 14 & 21 & 22 & $\mathrm{n} / \mathrm{a}$ \\
\hline & & 0.7 & 0.007 & 2.9 & 1.33 & 0.76 & 16 & 18 & 29 & 30 & $\mathrm{n} / \mathrm{a}$ \\
\hline [40] & $\begin{array}{l}1 \mathrm{M}, 28 \mathrm{y} \\
82 \mathrm{~kg}\end{array}$ & 0.4 & 0.04 & 4.1 & 0.33 & 0.24 & 34 & 48 & 32 & 40 & $\mathrm{n} / \mathrm{a}$ \\
\hline \multirow[t]{2}{*}{ [41] } & $\begin{array}{l}23 \mathrm{~F}, \\
20.9 \mathrm{y} \\
63.1 \mathrm{~kg}\end{array}$ & 0.4 & 0.025 & 2.1 & $\mathrm{n} / \mathrm{a}$ & 0.30 & 9 & $\mathrm{n} / \mathrm{a}$ & 3 & 23 & $\mathrm{n} / \mathrm{a}$ \\
\hline & & 0.3 & 0.025 & 1.9 & $\mathrm{n} / \mathrm{a}$ & 0.24 & 23 & $\mathrm{n} / \mathrm{a}$ & 12 & $\mathrm{n} / \mathrm{a}$ & $\mathrm{n} / \mathrm{a}$ \\
\hline
\end{tabular}

Most computational models represented the ACL ligament as a straight-line 1D segment with pre-defined, non-linear elastic material properties with its insertion sites based on cadaveric measurements ${ }^{11,23,37-39}$. In a computationally more involved approach, Kiapour et al. ${ }^{33}$ developed an anatomically-based Finite Element (FE) model of the knee joint based on CT/MRI images of one female athlete (25 years old). The anatomically-based FE model accurately captured the 3D spatial orientation of the fibres inside the ligaments to analyse the strain in the different bundles. The model was then later validated against in vitro results by the same Authors ${ }^{29}$, and subsequently adopted to better interpret experimental findings on the relationship between multi-planar knee kinematics and ACL loading from cadaveric testing ${ }^{30}$. While the model accurately captured the 3D fibre orientation of the ligaments, the muscle-tendon structures were represented by straight-line segments with their line-of-action taken from the literature. The $\mathrm{H}: \mathrm{Q}$ ratio prior to landing was pre-set at 0.67 , and details on the material properties of the muscle tissue and the magnitudes of the muscle-tendon forces during dynamic simulation were unfortunately lacking.

\section{Discussion}

Muscles are the primary active joint stabilisers that help to protect knee ligaments from injury. As a result, it is assumed that the co-activation of antagonistic muscles prior to and during landing plays a critical role in balancing the forces across the knee joint, and thus reducing the risk of $A C L$ injury. Interestingly, no apparent trend between $A C L$ loading and $H: Q$ ratio prior/during landing was found across the literature, with an isolated increase of either the quadriceps or the hamstrings muscle-tendon forces during landing leading to a decrease in ACL loading. It appears that ACL loading cannot be explained by the mechanisms of muscle-tendon forces alone, but likely results from a complex interaction between the external forces (e.g. VIF), the knee joint kinematics, the knee joint anatomy, as well as the timing and magnitude of peak muscular activity. Here, the in vitro results of three studies suggest that the timing of peak muscletendon forces may be crucial to reducing ACL loading $5,19,32$. The importance of neuromuscular timing was emphasised in related work by Taylor et al. ${ }^{16}$ who found a peak ACL strain $55 \mathrm{~ms}$ before landing at the minimum of knee flexion angle based on in vivo image-based analysis in eight subjects ( 8 males, average age 26 years). It was suggested that the timing of antagonistic muscle activity before landing may be crucial for successfully stabilizing the knee joint during impact; and that disruptions or perturbations prior to contact may lead to ligament overloading and injury. Unfortunately, the accurate derivation of force trajectories of antagonistic muscles during jump landing remains very challenging because of remaining limitations in measuring or computationally simulating the over-determined dynamical system that comprises the lower limbs.

Computational models based on inverse dynamics analysis in combination with EMG-based or static optimisation have generally been adopted to derive 
muscle-tendon forces during landing in situ (Tab. III). The derivation of muscle-tendon forces using static optimisation necessitates distributing the net intersegmental forces across synergistic and antagonistic muscles, which leads to a problem of indeterminate nature that is generally solved using quasi-static optimisation techniques ${ }^{43}$. For low-speed exercises, the quasi-static equilibrium condition holds true under the assumption that the angular acceleration of each segment is negligible; however, this is not the case for high-speed exercises associated with non-contact ACL rupture. Static optimisation techniques are generally not sufficient for predicting antagonistic muscle activity that does not occur with the goal of minimizing stress but rather to e.g. stabilize joints and maintain joint integrity. Ideally, computational methods based on forward dynamics simulations are used to predict muscle activation patterns during high-speed movements such as jump landing, and then analyse how inter-muscular control affects ACL loading ${ }^{43}$. Forward dynamics simulation is a method of systematic trial and error, and reflects the process by which an athlete optimizes control of muscle recruitment and physiological strength for best performance of explosive movements. In general, forward dynamics simulations are computationally expensive as the basic equations of motion have to be integrated twice over time. However, advancements in numerical techniques have led to the introduction of the computed muscle control algorithm to determine a set of muscle excitation patterns that optimally matches in vivo kinematic data in a computationally efficient manner ${ }^{44}$. Two studies have adopted the computed muscle control algorithm to analyse the influence of landing technique on $\mathrm{ACL}$ loading during jump landing in young female athletes ${ }^{11,38}$. Further work in this direction is needed to elucidate the influence of changes in antagonistic muscle activity on ligament (over)loading.

In general, the consideration of physiologically-based muscle activity for analysing ACL loading during in vitro cadaveric testing, as well as in situ computational modelling, remains highly compromised. Muscletendon structures for computational simulations have generally been represented using non-linear elastic 1D elements to reduce computational costs, with the muscle's anatomical line-of-actions, cross sectional areas and material properties estimated based on reported values in the literature; while 1D cables with a given stiffness and pre-tension have been adopted to replicate muscles during cadaveric testing. However, the muscle force magnitudes and directions during dynamic movement are affected by time-dependent changes in muscle-tendon lengths, lever arms, knee and hip joint angles and their angular velocities, as well as the given muscle activation levels and cross sectional areas. Slight changes in the muscle line of action have a considerable impact on the muscle's lever arm, which in turn influence the moment generating power, and thus the entire dynamics of the joint. Cassidy et al. ${ }^{32}$ was the only group who applied physiologically-based muscle force profiles to a cadaveric knee joint to measure $A M-A C L$ strain magnitudes during jump landing. The muscle-tendon forces and lever arms from computational modelling based on in vivo kinematic and kinetic data of one female amateur athlete were used to calculate the equivalent muscle group forces, which were then applied to the cadaveric knee to replicate the moments as predicted by the computational model. Unfortunately, the study was limited to one subject and exact details on the magnitudes of the applied VIF, peak hamstring and quadriceps forces were missing.

The coupled motion between the hip, knee and ankle joint dynamically affects the force-generating properties of all muscle structures in the lower limbs, whereby the stretch-strain response of the muscle-tendon structures and ligaments further depends on the speed of movement ${ }^{18}$. The importance of considering the dynamic coupling between the hip, knee and ankle joint when analysing ACL loading during jump landing has been clearly demonstrated in different work $^{19,37}$. Based on cadaveric testing, it has been demonstrated that AM-ACL strain is inversely related to the available range of internal femoral rotation during jump landing, suggesting that increased pre-tension of the external hip rotators may cause an increase in ACL strain due to an increase in internal tibial rotation with coupled anterior tibial translation ${ }^{19}$. In different work based on computational modelling, it was demonstrated that a change in the ankle plantar flexion angles significantly affected knee joint kinematics and kinetics, and thus ACL loading ${ }^{37}$. Only three studies were found which reported on strain rate magnitudes from DVRT measurements during cadaveric testing (Tab. II). However, none of these studies further analysed the relationship between joint dynamics, speed of loading and potential increase in ACL injury risk under sudden stretch during high-impact loading. Here, it is important to remember that ligaments and muscle-tendon structures have visco-elastic material properties that are characterised by a velocity-dependent response to sudden stretch. As such, the rate at which the muscles and ligaments are stretched during landing is likely to impact on the resulting forces within the soft tissue, and thus the risk of ACL injury.

\section{Conclusion}

The key finding from this systematic review of the literature is that both peak $A C L$ strain and peak $A C L$ force during jump landing appear to be reduced if the tensile stiffness (passive resistance to stretch) of the quadriceps $5,20,21,32$ or the hamstrings ${ }^{26,41}$ is increased during landing (Tabs. II, IV). These results suggest that increased hip flexion during landing may help in reducing $A C L$ strain by lengthening the hamstrings, and thus increasing its passive resistance to stretch; while increased tensile stiffness of the quadriceps, for example associated with increased muscular crosssectional area in males compared to females, may help in stabilising the joint during landing, and thus 
protecting the passive soft-tissue structures from overloading. However, the applied VIF, knee joint position and muscle-tendon forces prior to landing were found to span a wide range of magnitudes across both in vitro cadaveric and in situ computational studies, which severely limited our ability to analytically compare the study results.

In general, advancements in computational modelling and cadaveric simulations are needed to accurately capture the behaviour of the non-linear viscoelastic muscle-tendon structures during dynamic movement, and then systematically analyse the influence of changes in the timing and the magnitude of muscletendon forces on peak ACL loading during jump landing. In the future, forward dynamics musculoskeletal modelling may provide a powerful tool to analyse how alterations in muscle activation affect $A C L$ loading during high-impact movements such as jump landing. The insights from such analyses will be essential to improve the current understanding of the biomechanical mechanisms underlying ligament overloading, with the ultimate goal to design targeted preventive therapy (e.g. muscle strengthening exercises) as well as patient-specific treatment following ACL injury.

\section{Conflict of interest}

The Author has no financial or personal relationships with other people or organizations that could inappropriately influence their work.

\section{References}

1. Beynnon BD, Vacek PM, Newell MK, et al. The Effects of Level of Competition, Sport, and Sex on the Incidence of FirstTime Noncontact Anterior Cruciate Ligament Injury. The American journal of sports medicine. 2014;42:1806-1812.

2. Gianotti SM, Marshall SW, Hume PA, Bunt L. Incidence of anterior cruciate ligament injury and other knee ligament injuries: a national population-based study. J Sci Med Sport. 2009;12: 622-627.

3. John R, Dhillon MS, Syam K, Prabhakar S, Behera P, Singh H. Epidemiological profile of sports-related knee injuries in northern India: An observational study at a tertiary care centre. Journal of clinical orthopaedics and trauma. 2016;7:207-211.

4. Bates NA, Myer GD, Shearn JT, Hewett TE. Anterior cruciate ligament biomechanics during robotic and mechanical simulations of physiologic and clinical motion tasks: a systematic review and meta-analysis. Clin Biomech (Bristol, Avon). 2015; 30:1-13.

5. Hashemi J, Breighner R, Jang TH, Chandrashekar N, EkwaroOsire S, Slauterbeck JR. Increasing pre-activation of the quadriceps muscle protects the anterior cruciate ligament during the landing phase of a jump: an in vitro simulation. Knee. 2010;17:235-241.

6. Kazemi M, Dabiri Y, Li LP. Recent advances in computational mechanics of the human knee joint. Comput Math Methods Med. 2013;2013:718423.

7. Pappas E, Zampeli F, Xergia SA, Georgoulis AD. Lessons learned from the last 20 years of ACL-related in vivo-biomechanics research of the knee joint. Knee Surg Sports Traumatol Arthrosc. 2013;21:755-766.
8. Hewett TE, Ford KR, Hoogenboom BJ, Myer GD. Understanding and preventing acl injuries: current biomechanical and epidemiologic considerations - update 2010. North American journal of sports physical therapy. NAJSPT. 2010;5:234251.

9. Hewett TE, Ford KR, Myer GD. Anterior cruciate ligament injuries in female athletes: Part 2, a meta-analysis of neuromuscular interventions aimed at injury prevention. The American journal of sports medicine. 2006;34:490-498.

10. Boeth H, Duda GN, Heller MO, et al. Anterior cruciate ligament-deficient patients with passive knee joint laxity have a decreased range of anterior-posterior motion during active movements. The American journal of sports medicine. 2013; 41:1051-1057.

11. Kar J, Quesada PM. A numerical simulation approach to studying anterior cruciate ligament strains and internal forces among young recreational women performing valgus inducing stop-jump activities. Ann Biomed Eng. 2012;40:1679-1691.

12. Padulo J, Oliva F, Frizziero A, Maffulli N. Muscles, Ligaments and Tendons Journal - Basic principles and recommendations in clinical and field science research: 2016 Update. MLTJ. 2016;6(1):1-5.

13. Thomas J, Brunton J, Graziosi S. EPPI-Reviewer 4: software for research synthesis. EPPI-Centre Software. London: Social Science Research Unit: Institute of Education; 2010.

14. Cerulli G, Benoit DL, Lamontagne M, Caraffa A, Liti A. In vivo anterior cruciate ligament strain behaviour during a rapid deceleration movement: case report. Knee Surg Sport $\operatorname{Tr}$ A 2003;11:307-311.

15. Heinrich D, van den Bogert AJ, Nachbauer W. Relationship between jump landing kinematics and peak $A C L$ force during a jump in downhill skiing: A simulation study. Scand J Med Sci Sport. 2014;24:E180-E187.

16. Taylor KA, Terry ME, Utturkar GM, et al. Measurement of in vivo anterior cruciate ligament strain during dynamic jump landing. J Biomech. 2011;44:365-371.

17. Zhang YX, Liu GY, Xie SQ. Biomechanical simulation of anterior cruciate ligament strain for sports injury prevention. Comput Biol Med. 2011;41:159-163.

18. Withrow TJ, Huston LJ, Wojtys EM, Ashton-Miller JA. The effect of an impulsive knee valgus moment on in vitro relative ACL strain during a simulated jump landing. Clin Biomech (Bristol, Avon). 2006;21:977-983.

19. Beaulieu ML, Oh YK, Bedi A, Ashton-Miller JA, Wojtys EM Does limited internal femoral rotation increase peak anterior cruciate ligament strain during a simulated pivot landing? The American journal of sports medicine. 2014;42:2955-2963.

20. Lipps DB, Oh YK, Ashton-Miller JA, Wojtys EM. Morphologic characteristics help explain the gender difference in peak anterior cruciate ligament strain during a simulated pivot landing. The American journal of sports medicine. 2012;40:32-40.

21. Lipps DB, Oh YK, Ashton-Miller JA, Wojtys EM. Effect of increased quadriceps tensile stiffness on peak anterior cruciate ligament strain during a simulated pivot landing. J Orthop Res. 2014:32:423-430.

22. McLean SG, Oh YK, Palmer ML, et al. The relationship between anterior tibial acceleration, tibial slope, and ACL strain during a simulated jump landing task. J Bone Joint Surg Am. 2011;93:1310-1317.

23. Oh YK, Kreinbrink JL, Wojtys EM, Ashton-Miller JA. Effect of axial tibial torque direction on $\mathrm{ACL}$ relative strain and strain rate in an in vitro simulated pivot landing. J Orthop Res. 2012;30: 528-534.

24. Oh YK, Lipps DB, Ashton-Miller JA, Wojtys EM. What strains the anterior cruciate ligament during a pivot landing? The American journal of sports medicine. 2012;40:574-583.

25. Withrow TJ, Huston LJ, Wojtys EM, Ashton-Miller JA. The relationship between quadriceps muscle force, knee flexion, and 
anterior cruciate ligament strain in an in vitro simulated jump landing. The American journal of sports medicine. 2006;34: 269-274.

26. Withrow TJ, Huston LJ, Wojtys EM, Ashton-Miller JA. Effect of varying hamstring tension on anterior cruciate ligament strain during in vitro impulsive knee flexion and compression loading. J Bone Joint Surg Am. 2008;90:815-823.

27. Levine JW, Kiapour AM, Quatman CE, et al. Clinically relevant injury patterns after an anterior cruciate ligament injury provide insight into injury mechanisms. The American journal of sports medicine. 2013;41:385-395.

28. Kiapour AM, Quatman CE, Goel VK, Wordeman SC, Hewett TE, Demetropoulos CK. Timing sequence of multi-planar knee kinematics revealed by physiologic cadaveric simulation of landing: implications for ACL injury mechanism. Clin Biomech (Bristol, Avon). 2014;29:75-82.

29. Kiapour AM, Wordeman SC, Paterno MV, et al. Diagnostic value of knee arthrometry in the prediction of anterior cruciate ligament strain during landing. The American journal of sports medicine. 2014;42:312-319.

30. Quatman CE, Kiapour AM, Demetropoulos CK, et al. Preferential loading of the ACL compared with the MCL during landing: a novel in sim approach yields the multiplanar mechanism of dynamic valgus during ACL injuries. The American journal of sports medicine. 2014;42:177-186.

31. Weinhold PS, Stewart JD, Liu HY, Lin CF, Garrett WE, Yu B. The influence of gender-specific loading patterns of the stopjump task on anterior cruciate ligament strain. Injury. 2007; 38:973-978.

32. Cassidy K, Hangalur G, Sabharwal P, Chandrashekar N. Combined in vivo/in vitro method to study anteriomedial bundle strain in the anterior cruciate ligament using a dynamic knee simulator. J Biomech Eng. 2013;135.

33. Kiapour A, Kiapour AM, Kaul V, et al. Finite element model of the knee for investigation of injury mechanisms: development and validation. J Biomech Eng. 2014;136.

34. Shin CS, Chaudhari AM, Andriacchi TP. The influence of deceleration forces on ACL strain during single-leg landing: a simulation study. J Biomech. 2007;40:1145-1152.

35. Shin CS, Chaudhari AM, Andriacchi TP. The effect of isolated valgus moments on $\mathrm{ACL}$ strain during single-leg landing: a simulation study. J Biomech. 2009;42:280-285.

36. Shin CS, Chaudhari AM, Andriacchi TP. Valgus plus internal rotation moments increase anterior cruciate ligament strain more than either alone. Med Sci Sports Exerc. 2011;43:14841491.

37. Kernozek TW, Ragan RJ. Estimation of anterior cruciate ligament tension from inverse dynamics data and electromyography in females during drop landing. Clin Biomech (Bristol, Avon). 2008;23:1279-1286.

38. Laughlin WA, Weinhandl JT, Kernozek TW, Cobb SC, Keenan KG, O'Connor KM. The effects of single-leg landing technique on ACL loading. J Biomech. 2011;44:1845-1851.

39. Mokhtarzadeh $\mathrm{H}$, Yeow $\mathrm{CH}$, Hong Goh JC, Oetomo D, Malekipour F, Lee PV. Contributions of the soleus and gastrocnemius muscles to the anterior cruciate ligament loading during single-leg landing. J Biomech. 2013;46:1913-1920.

40. Pflum MA, Shelburne KB, Torry MR, Decker MJ, Pandy MG. Model prediction of anterior cruciate ligament force during drop-landings. Med Sci Sports Exerc. 2004;36:1949-1958.

41. Southard J, Kernozek TW, Ragan R, Willson J. Comparison of estimated anterior cruciate ligament tension during a typical and flexed knee and hip drop landing using sagittal plane knee modeling. Int J Sports Med. 2012;33: 381-385.

42. Seth A, Sherman M, Reinbolt JA, Delp SL. OpenSim: a musculoskeletal modeling and simulation framework for in silico investigations and exchange. Procedia IUTAM. 2011;2:212232.

43. Schellenberg F, Oberhofer K, Taylor WR, Lorenzetti S. Review of Modelling Techniques for In Vivo Muscle Force Estimation in the Lower Extremities during Strength Training. Computational and Mathematical Methods in Medicine. 2015; 2015:12

44. Thelen DG, Anderson FC. Using computed muscle control to generate forward dynamic simulations of human walking from experimental data. J Biomech. 2006;39:1107-1115.

45. Moher D, Liberati A, Tetzlaff J, Altman DG. Preferred reporting items of systematic review and meta-analyses: the PRISMA statement. Deut Med Wochenschr. 2011;136:E25. 